\title{
AS ARTES DE GOVERNO E A TECNOLOGIAS DE SI: DESAFIOS À FUNÇÃO-EDUCADOR
}

\section{Jonas Rangel de Almeida* Pedro Ângelo Pagni*}

Resumo: O objetivo é discutir os desafios das artes de governo e das tecnologias de si à função-educador. A possível acusação de impotência diante das relações microfísicas de poder levou Foucault à elaboração da noção de governo dos homens e a traçar uma história das práticas de subjetivação do Ocidente. Na escola moderna é possível observar a imbricação dessas artes de governo e das técnicas de si desde o início de sua emergência, no século XVIII, de um lado, como mecanismo de disciplinarização dos corpos para torná-los dóceis e úteis ao trabalho fabril, e de outro lado, como tecnologia de produção de sujeitos que governam a si mesmo, dirimindo assim, as possibilidades de revoltas e sublevações à ordem instituída. Considera-se, pois que o dilema do educador só pode se resolver quando por ocasião das liberações houver também investimento ético nas práticas de si.

Palavras-chave: Artes de governo; Tecnologias de si; Função-educador; Educação; Liberdade.

Resumen: El objetivo es discutir los desafíos de las artes del gobierno y tecnologías de si para el papel del educador. La posible acusación de impotencia frente a las relaciones microfísicas de poder llevó Foucault a elaborar la noción del gobierno de los hombres y trazar una historia de las prácticas de subjetividad occidentales. En la escuela moderna, es posible observar la imbricación de estas artes y auto-técnicas gubernamentales desde el comienzo de su surgimiento, en el siglo XVIII, por un lado, como un mecanismo para disciplinar a los organismos para que sean dóciles y útiles para el trabajo de fábrica, y por otro lado, como tecnología para la producción de sujetos que se gobiernan a sí mismos, resolviendo así las posibilidades de revueltas y agitaciones al orden instituido. Por lo tanto, se considera que el dilema del educador solo puede resolverse cuando hay procesos de liberación también hay inversiones éticas en las prácticas de sí mismo.

Palabras claves: Arte del gobierno; Auto tecnologías; Función-educador; Educacíon; Libertad.

\section{Introdução}

No livro Educação: um tesouro a descobrir: relatório para a UNESCO da Comissão Internacional sobre Educação para o

\footnotetext{
Doutorando em Educação pelo PPGE, UnespMarília. E-mail: jradavisao@gmail.com

*** Professor Livre-Docente do Departamento de Administração Escolar da Faculdade de Filosofia e Ciências de Marília, Unesp-Marília.

E-mail: pedropagni@gmail.com.
}

século XXI (DELORS, 2003) os quatro pilares da educação se apresentam subsequentemente como: aprender a conhecer; aprender a fazer; aprender a viver juntos; e aprender a ser. Reconhecido mundialmente, esse relatório Delors é amplamente recomendado como documento norteador para a criação de uma educação compatível com os desafios do mundo contemporâneo radicalmente plural, diverso e desigual. 
O objetivo deste texto é oferecer uma análise em relação a esses pilares - que se tornaram mais nítidos ao passo que forem expostas as matrizes tecnológicas de formação humana - discutindo a imbricação entre governo dos homens, as tecnologias e o lugar que ocupa a função-educador nas experiências de formação em instituições escolares regulada pelas práticas divisoras.

Para discutir os lugares que ocupa a função-educador no sentido concebido por Carvalho (2010), faz-se necessário analisar quais as configurações que a escola atualmente está assumindo. Perante esse desafio torna-se preciso se colocar no limite do domínio da governamentalidade política em direção da constituição de um governo de si e dos outros - consoante o ensino de Foucault em seus últimos cursos. Apoiando-se na interpretação de Pagni (2014) significa realizar um deslocamento à ética da constituição dos sujeitos que atuam no espaço escolar. Com isso, pode-se colocar ênfase no processo de formação à medida que implica na autotransformação dos sujeitos diante de acontecimentos, isto é, a criação de "[...] campo de experimentação para a criação de outro tipo de interpelações subjetivas e como indicativo de emergência de uma nova ética." (PAGNI, 2016, p. 345). Isso, implica, na adoção de uma metodologia sutil de experimentação de si mesmo face às tensões acionadas pelos dispositivos de governo da subjetividade que atravessam as instituições educacionais. Em consonância com a perspectiva desenvolvida por Pagni (2014b), particularmente no que se refere às diferentes experiências, ou, tradições de pensamento que habitam Filosofia da Educação como um campo de pesquisa e ensino comprome- tido com a criação de modos de resistência. Portanto, suscita-se uma atitude ética atenta à constituição de um ethos múltiplo e diversificado que somos nós. Aspira-se a uma arte da existência que se atenha a vida e provoque os educadores à maestria de si mesmo (PAGNI, 2014a); uma maneira de assumir o governo de si como cuidado ético consigo e com os outros; e, finalmente, a adoção de uma pragmática do ensino que não privilegie a mera transmissão de competências e habilidades, mas que interpele o sujeito a modificar-se a si mesmo, seu modo de ser.

De acordo com Gallo (2007) e Freitas (2013), as primeiras leituras da obra de Foucault, ou, a chamada primeira onda de recepção do seu pensamento deu-se durante quase duas décadas no campo da Filosofia da Educação ocorreu quase que exclusivamente graças às contribuições de Vigiar $e$ Punir (1997) e dos textos presentes na coletânea Microfísica do poder. Nesse ponto de vista, as escolas, com seus saberes e suas práticas foram concebidas, em virtude dos micropoderes disciplinadores que a atravessam como parte de um processo de utilização e docilização dos corpos - anátomopolítica. Mas, essa situação mudou após a edição e publicação dos cursos que o filósofo proferiu no Collège de France após assumir a cadeira de história dos sistemas de pensamento. Essa conjuntura tem permitido aos pesquisadores e intérpretes da reflexão foucaultiana uma reavaliação preciosa de suas contribuições e novos estudos emergentes no campo da filosofia da educação. Essas novas lições e análises desenvolvidas não desprestigiam a dimensão analítica das relações de poder fazendo com que percam seu potencial crítico. Com efeito, as publicações dos 
cursos de Foucault tornaram a discussão mais rica, complexa e atual do que nunca, garantindo outras possibilidades de atualização do diagnóstico do presente.

Durante duas décadas, a hipótese que Deleuze (1992) enunciou em Post-scriptum sobre as sociedades de controle foi uma referência fundamental sobre uma possível transição da sociedade disciplinar para os domínios dos dispositivos abertos de controle. Intérpretes, comentadores e pesquisadores das Ciências Humanas e da Filosofia recorriam a esse ensaio na tentativa de repensar o diagnóstico foucaultiano de sujeição às máquinas de poder em direção à nossa atualidade. Os que datam os anos finais década de 1970 e início de 1980 trouxeram inúmeras possibilidades de atualização desse tema. Como mostrava Collin Gordon (1992), a problemática da razão de governo mostravanos um Foucault muito preocupado em se aproximar do presente, para além das análises das disciplinas. Com a publicação dos cursos e conferências em espanhol e português os estudos sobre a governamentalidade adquirem ampla difusão, garantindo acesso imediato aos ditos e escritos do próprio autor.

Em 1976, Foucault (2007) publica $A$ vontade de saber, comunicando seu ambicioso projeto de uma história da sexualidade em seis volumes. Condensando parte dos cursos proferidos pelo filósofo, até então a tese mais famosa do livro, diz que a sexualidade nas sociedades ocidentais não era produto de uma repressão primária, mas, da intensificação de mecanismos que eletrizavam os corpos em uma economia produtiva de poder. Entre os temas abordados, Foucault enunciou sua notável hipótese de resis- tência ao poder, após isso, surgiram críticas relativas que o acusavam de incapacidade em cruzar a linha para o outro lado do poder. Logo, depois do descanso sabático, no curso de 1978, aparece à noção de governo dos homens. De certo modo, Foucault está respondendo as críticas que recebeu de seu colega Deleuze em uma carta de 1977, conhecida, hoje, por Desejo e Prazer. Entusiasta do pensamento de Foucault, Deleuze, que enxergou novidades nas análises microfísicas nas páginas de Vigiar e punir (1997) mostrase descontente com andamento das pesquisas do seu colega. Entre os perigos mencionados está o de retornar a uma forma análoga de sujeito constituinte e, além de miniaturizar nas relações de poder o conceito global de Estado.

O lugar das múltiplas racionalidades de governo nos estudos foucaultianos pode ser reconstituído, de um lado, por intermédio da leitura e interpretação cursos Segurança, território e população (Foucault, 2008b) e $O$ nascimento da biopolítica (Foucault, 2008c) proferidos ao final década de 1970; e, de outro lado, de uma análise que compreendeu a recepção que os temas da biopolítica (ARAYA, 2014) e das artes de governo (ROSE, 1997; LAZZARATO, 2014) neoliberais tiveram entre filósofos, teóricos sociais e intelectuais da educação. Neste sentido, consolida-se uma matriz de intérpretes do pensamento de Foucault que têm se esforçado em mostrar os modos através dos quais os dispositivos estratégicos de governo da conduta dos indivíduos operam na atualidade em proveito da produção de subjetividades empresariadas (DARDOT; LAVAL, 2016), ou, endividadas (LAZZARATO, 2014). Tal perspectiva adquire relevância para o prosse- 
guimento desta pesquisa, pois, demarca o espraiamento de novas racionalidades governamentais estatais por todo o tecido social (MUSSETA, 2009). Neste sentido, VeigaNeto (1999), entende que as instituições escolares, atualmente, constituem o lócus, onde as novas tecnologias de governo são, ao mesmo tempo, inventadas e aplicadas, pois, pertencem ao dispositivo que dissemina $e$ arregimenta seus modos de objetivação $e$ subjetivação. A formação ética - o ethos, isto é, a maneira de ser e de se constituir como sujeito - do professor nas instituições educacionais encontra-se demarcada ao campo das novas racionalidades econômicas que tendem a privilegiar a produção de expertises responsáveis por converter a sociedade civil no laboratório do homo economicus (HAMANN, 2012; ROSE, 1997).

Desse modo, a análise da governamentalidade neoliberal e dos cursos sobre a cultura antiga têm servido como ferramenta indispensável para os pesquisadores que buscam por novos domínios, seja na Educação, na Filosofia ou na Teoria Social, sem ter que recorrer a qualquer conceito substancial de sujeito, tampouco retomando a noção jurídica e transcendental de Estado como lócus privilegiado para analisar as relações de poder ${ }^{3}$.

\footnotetext{
${ }^{3}$ É sob auspício dessas novas ferramentas que os filósofos da educação - em particular, do campo de estudos foucaultianos - têm analisado os problemas educacionais contemporâneos, por exemplo: a questão da inclusão escolar Veiga-Neto (2001), Lopes (2007), Carvalho (2015), e, Pagni (2015). As relações de gênero na escola Falchi (2013); o discurso da mídia Fischer (2002); sobre a constituição das subjetividades escolares Pagni (2010); o novo currículo cultural Silva (2010). A história das políticas de inclusão a começar do governo FHC, Lula e Dilma, por exemplo, foi objeto de Rech (2010), Santos (2010), Lockmann (2010), Menezes (2011). Como analítica acerca do desenvolvimento de políticas de assistên-
}

\section{As artes de governo, a discplina e a escola}

Em vista dos recentes estudos sobre o processo de governamentalização e dos modos de subjetivação na cultura antiga, podese construir outro olhar acerca da instituição escolar. Neste texto, interessa-nos, sobretudo, o lugar que o educador ocupa nela com vistas a engendrar como catalisador químico focos de resistência para "[...] promover dentro dela esse processo e dar visibilidade para as formas de agenciamentos e de existências comuns que já a habitam" (PAGNI, 2018, p. 202). Sob essa perspectiva, interessa menos analisar a partir de uma teoria normativa do funcionamento das instituições escolares, e mais, na senda aberta pela genealogia da razão de governo proposta por Foucault (2008b; 2008c). Nessa, o que importa é passar à exterioridade das práticas históricas mostrando em que medida 'educar', 'educar-se', 'formar', 'formar-se' foram problematizadas enquanto uma realidade governável pelos regimes políticos de verdade. Contudo, isso não significa que se perderá de horizonte a indissociável herança disciplinar das práticas escolares, pelo contrário, a tarefa integra os diversos modos através das quais as escolas participam e arregimentam certos dispositivos estratégicos de governo atuantes na constituição das subjetividades.

Para realizar um exame atento da questão é necessário seguir as indicações presentes nos cursos de Foucault somandoas com outros indícios oferecidos em suas

\footnotetext{
cia social deve-se consultar a pesquisa de Bujes (2001), ou, Lockmann (2013). Na educação especial o estudo de Pieckowski (2014), e, Silva (2017). Outros temas como o voluntariado: Klein (2005); racismo Kern (2016); perfomatividade Hattge (2014); empreendedorismo Calixto (2013); e avaliação pedagógica Camillo (2008).
} 
intervenções públicas, a saber, na entrevista O sujeito e o poder (1995) e no seminário de 1982, na Universidade de Toronto intitulado Tecnologías del yo (1990). A meu ver, Pagni (2010) foi um dos primeiros a enunciar essa relação no campo da Filosofia da Educação. Partindo das noções foucaultianas de bloco de capacidades-comunicação-poder, Pagni (2010) concebe a instituição escolar como um processo de subjetivação moral, tanto dos alunos, quanto dos professores, mediatizada, por um regime de comunicação esvaziado de uma problematização ética da constituição do sujeito, ou, de prática de si. No ensaio O ingovernável dos corpos e das multidôes na escola, Pagni (2018), escreve

[...] na modernidade, a arte pedagógica se exerce em instituições como a família e a escola para produzir um governo biopolítico sobre a população e anátomo-político sobre os corpos, em vistas a tornar estes últimos dóceis e produtivos e aquela governável. Para isso, particularmente, essa arte se exerce sobre a infância com o intuito de formar essa população, enquanto que na escola se exerce historicamente como blocos de comunicação-capacidade-poder. (PAGNI, 2018, p. 197).

Os alvos privilegiados são a população e a infância. Para construir sua análise Pagni (2018) refere-se à entrevista $O$ sujeito e o poder (1995), concedida dois anos antes da morte de Foucault. Para o filósofo francês a instituição escolar se configura como um bloco de comunicação-capacidadepoder. Uma noção que pode nos oferecer pistas para circunscrever os lugares que $\mathrm{o}$ educador atua, bem como, o papel que a instituição educacional cumpre nos quadros da razão governamental. Com isso, mira-se na dinâmica das lutas contemporâneas e na questão da constituição ética do sujeito.

Para compreender esse bloco é preciso distinguir as relações de poder das relações de força que exercemos sobre as coisas, normalmente que nos capacita para produzir, consumir e destruir, isto é, daquelas aptidões diretamente inscritas no corpo e mediatizadas por dispositivos instrumentais. Foucault (1990) chama essa matriz de tecnologia de produção. $\mathrm{O}$ que se pode entender como um certo saber fazer. Também, se deve distinguir as relações de poder das relações de comunicação que servem para transmitir informações através da língua, ou, de um sistema de signos. Uma tecnologia de signo. Na visão de Foucault (1995) as relações de poder ocorrem no domínio empírico do que acontece. O poder é da ordem das ações exercidas pelos indivíduos sobre a conduta dos outros indivíduos, ações sobre ações, passadas, presentes e, eventualmente, futuras. Tecnologia de poder que tem a finalidade de dirigir a conduta do outro. Esses três domínios não existem de forma separada $e$ independente como se fosse possível funcionar um domínio das técnicas finalizadas do trabalho sem um do regime de comunicação, do signo e da fabricação do sentido; ou, esse último funcionar sem a matriz de dominação dos meios de coação, de desigualdade e de ação dos homens sobre os homens. As tecnologias articulam-se, imbricam-se $e$ apóiam-se mutuamente, ainda que cada domínio resguarde uma especificidade própria que não deve ser prescindida. Diz Foucault:

[...] não há, numa sociedade dada, um tipo ideal de equilíbrio entre atividades finalizadas, os sis- 
temas de comunicação $e$ as relações de poder. Há, antes, diversas formas, diversos lugares, diversas circunstâncias ou ocasiões em que estas inter-relações se estabelecem sobre um modelo específico. Porém, há também blocos nos quais o ajuste das capacidades, os feixes de comunicação $e$ as relações de poder constituem sistemas regulados e concordes. Seja, por exemplo, uma instituição escolar: sua organização espacial, o regulamento meticuloso que rege sua vida interior, as diferentes atividades aí organizadas, os diversos personagens que aí vivem e se encontram cada um com uma função, um lugar, um rosto bem definido - tudo isso constitui um bloco de capacidade-comunicação-poder. A atividade que assegura o aprendizado $e$ a aquisição de aptidões ou tipo de comportamento aí se desenvolve através de todo um conjunto de comunicações reguladas (lições, questões e respostas, ordens exortações, signos codificados de obediência, marcas diferenciais do valor de cada um $e$ dos níveis de saber) e através de toda uma série de procedimentos de poder (enclausuramento, vigilância, recompensa e punição, hierarquia piramidal). (FOUCAULT, 1995, p. 241).

As chamadas disciplinas, alargando seu sentido terminológico, constituem esse ajuste tecnológico de fórmulas refletidas dos domínios na constituição dos blocos. Por disciplinas, neste caso, entende-se um esquema artificialmente claro e decantado no qual os sistemas de finalidade objetiva, as redes de comunicação $e$ as relações de po- der se articulam e se sobrepõem uns com relação aos outros. Elenca Foucault:

[...] aquilo que se deve compreender por disciplinarização das sociedades, a partir do século XVIII na Europa, não é, sem dúvida, que os indivíduos que fazem dela parte se tornem cada vez mais obedientes, nem que elas todas comecem a parecer com casernas, escolas, prisões; mas, que se tentou um ajuste cada vez mais controlado - cada vez mais racional e econômico - entre atividades produtivas, as redes de comunicação $e$ o jogo das relações de poder. (FOUCAULT, 1995, p. 242).

Em Vigiar e punir (1997) Foucault retraça, genealogicamente, o desaparecimento do Antigo Regime, marcado pela ideia de poder soberano que exercia o direito de vida e morte mostrando emergência do poder disciplinar responsável pela proliferação de mecanismos de controle sobre os corpos que visavam torná-lo dóceis e produtivos ao trabalho fabril. De acordo com Veiga-Neto (2004), a modernidade para Foucault inaugura a instituição dos saberes sobre o sujeito. Nesse sentido, implicam a passagem das sociedades de soberania para sociedades disciplinares. Um processo que é acompanhado da multiplicação das "instituições de encarceramento" por todo campo social como o exército, as escolas, os hospitais, as fábricas e as prisões.

Nessas instituições o poder se mostra de maneira mais excrescente. A família encerra o espaço o primeiro de reprodução social; a escola vem logo após como extensão da vigilância e lugar da docilização dos corpos; a fábrica encerra o indivíduo como 
força de trabalho para a reprodução das forças de produção; bem como, o hospital marca o encarceramento da doença, lugar de exclusão por excelência assim como a prisão.

Nos termos de Machado (2008, p.10), ocorre um "[...] verdadeiramente um desbloqueio tecnológico do poder [...]", com a disseminação de tecnologias que operam sobre o corpo individualizando-os, reordenando-os no espaço/tempo para fins de docilidade e de maior produtividade. Para Foucault (1997, p. 161) "[...] o indivíduo é sem dúvida o átomo fictício de uma representação ideológica da sociedade; mas é também uma realidade fabricada por essa tecnologia específica de poder que se chama a disciplina". Uma nascente economiapolítica do poder sobre os corpos.

O sucesso do poder disciplinar devese uso de certos instrumentos como: a instauração de um o olhar hierárquico, pois, "[o] exercício da disciplina supõe um dispositivo que obrigue pelo jogo do olhar; um aparelho onde as técnicas que permitem ver induzam a efeitos de poder, e onde, em troca, os meios de coerção tornem claramente visíveis aqueles sobre quem se aplicam". (FOUCAULT, 1997, p. 143); uma sanção normalizadora "[n]a oficina, na escola, no exército funciona como repressora toda uma micropenalidade do tempo (atrasos, ausências, interrupções das tarefas), da atividade (desatenção, negligência, falta de zelo), da maneira de ser (grosseria, desobediência), dos discursos (tagarelice, insolência), do corpo (atitudes "incorretas", gestos não conformes, sujeira), da sexualidade (imodéstia, indecência)". (FOUCAULT, 1997, p.149); e, um procedimento que lhe é específico, o exame que "[...] combina as técnicas da hierarquia que vigia $e$ as da sanção que normaliza. É um controle normalizante, uma vigilância que permite qualificar, classificar $e$ punir. Estabelece sobre os indivíduos uma visibilidade através da qual eles são diferenciados e sancionados". (1997, p.154). O exame põe em funcionamento complexas engrenagens, a um só tempo, um conjunto de relações de poder que permitem obter $e$ constituir saber sobre o sujeito na extração de saber dos indivíduos escrutinados. Graças ao exame elabora-se saber e poder sobre indivíduos. Por isso, o poder produz realidade, justamente, porque, engendra campos de objetos e novos rituais da verdade.

Graças ao alargamento do sentido das disciplinas do corpo presente nos textos do final da década de 1970 abre-se o horizonte da governamentalidade. Da analítica das relações de poder passa-se para as implicações das artes de governo, e posteriormente, para o eixo do governo de si e dos outros. $\mathrm{O}$ ajuste racional e econômico produzido nos cursos de 78 e 79 repousa nos termos de Collier (2011), na distinção que Foucault inaugura entre uma história das técnicas e uma história das tecnologias. $\mathrm{Na}$ primeira, trata-se de correlacionar como técnicas diversas se ajustam racional e economicamente ao modo de governo próprio da racionalidade governamental do liberalismo e do neoliberalismo; já no modelo das tecnologias detém-se na integração das diferentes matrizes de razão prática.

Dessa maneira, pode-se dizer que a instituição escolar subsiste no sentido da disciplina moderna que combina, regula, sobrepõe e articula as atividades produtivas, as redes de comunicação e os jogos de poder. 
Portanto, as disciplinas constituem o cerne da formação moderna ocidental oferecida nas instituições educacionais. Esse é o lugar no qual atua a função-educador (CARVALHO, 2010). Conforme Pagni:

[c]riada na modernidade para contribuir para a constituição de uma sociedade disciplinar, a educação escolar se concentrou na formação de sujeitos dóceis $e$ obedientes, sendo alterada parcialmente sua configuração para que os dispositivos de segurança adentrassem a instituição a partir da segunda metade do século passado e, mais recentemente, que tais dispositivos ganhassem outra configuração com as chamadas políticas de inclusão. Contudo, tais modulações empreendidas para atender as exigências dos blocos de poder-capacidadescomunicação, desenvolvidos historicamente, assim como as demandas dos segmentos sociais que passaram a ser integrados sob o signo do governo da população, não abrandam a função moralizante da educação, assumindo um papel estruturante na escola moderna. (PAGNI, 2018, p. 200).

Os pilares necessários estão presentes no bloco - fórmulas, questões, lições, ordens $e$ exortações - que asseguram a aquisição de certas habilidades, ou, nos termos da pedagogia atual, de determinadas competências. Aprende-se a conhecer com os sistemas de comunicação e signo; aprende-se a fazer no registro das tecnologias de produção de coisas; aprende-se a conviver assumindo e desempenhando um papel na condução da conduta do outro. Mas, como se aprende a ser nesse bloco enunciado por Foucault (1995)? De fato, segundo Pagni (2018) o ajuste entre as diferentes capacidades responsáveis pelo aparato técnico, as redes de comunicação e informação - que fazem circular enunciados e discursos verdadeiros $-e$ a dimensão agônica das relações estratégicas de poder opera no sentido de produzir um sujeito moral. Essa formação - disposição de aprender a ser - aparece no discurso filosófico e pedagógico atrelado a produção de uma moral do sujeito de conhecimento, assevera:

[...] desde o início da modernidade, as filosofias e teorias da educação também postulam que, por meio dessa obediência ou de uma suposta liberdade, a pedagogia seria responsável pela formação de sujeitos autônomos $e$ críticos. Ora, o fracasso dessa promessa pedagógica e filosófica educacional se deu, provavelmente, por entender a autonomia como um atributo da vontade e a crítica como um exercício da razão, restringindo conceitualmente esta última ao campo epistemológico e aquela a uma disposição política do sujeito. (PAGNI, 2018, p. 200).

De acordo com Pagni (2018), apesar da coesão desse bloco há resistência que tem seu princípio em certa rebeldia irrefletida. Novamente, remetendo-nos a entrevista de Foucault (1995) O sujeito e o poder: existe a ideia de que as lutas que se desenrolam com o declínio da sociedade disciplinar são as batalhas pelo governo de si mesmo, são as lutas em torno da individualização, questão do âmbito do pertencer a si mesmo que se tornaram preponderantes em nossa época. 
Ainda que as lutas contra a exploração e a dominação não tenham desaparecido, longe disso, os embates contemporâneos dirigemse, sobretudo, contra as técnicas de poder. Técnicas que "[...] aplica-se a vida cotidiana imediata que categoriza o indivíduo, marcao com sua própria individualidade, liga-o à sua própria identidade, impõe-lhe uma lei de verdade, que devemos reconhecer e que os outros têm que reconhecer nele." (FOUCAULT, 1995, p. 235). A relação entre essas batalhas pelo governo de si e as diferentes tecnologias é necessário remeter a outro texto que nos permite pensar em que medida esse ajuste racional e econômico implica na inter-relação entre tecnologias diversas, particularmente, uma tecnologia que permite aos indivíduos voltarem à atenção ao seu próprio corpo e alma, estabelecendo um vínculo indissolúvel entre a verdade mais íntima acerca de si mesmo e o modo correto de como se governar (ROSE, 2001).

A primeira vez que Foucault tornou público à questão das técnicas de si foi em novembro do ano de 1980, durante as de conferências na Universidade de Darthmouth, Estados Unidos. Já em Toronto em 1982, no seminário publicado como Tecnologías del yo, Foucault (1990) nos oferece algumas pistas para discutir as relações que podem ser estabelecidas entre o bloco capacidade-comunicação-poder e a constituição ética do sujeito. O objetivo de Foucault (1990) foi tratar de quatro tipos de tecnologias, cada uma delas, por sua vez, uma matriz de razão prática. Primeiro, as tecnologias de produção: que permitem transformar, produzir ou manipular coisas; segundo, as tecnologias de sistemas de signos: produz sentidos, símbolos e significações; terceiro, as tecnologias de poder: aquelas que determinam a conduta dos indivíduos e os submetem a certo tipo de fins. Se retroagir a exposição sobre o ajuste do bloco capacidadecomunicação-poder percebe-se a presença das três primeiras tecnologias. Esse conjunto tecnológico produz o processo de governamentalização: dispõe o governo de si por si e suas articulações com as relações que se estabelecem com os outros. Por fim, quarto, Foucault refere-se às tecnologias de si, por meio, das quais o indivíduo, por si mesmo, ou, com a ajuda dos outros, realizam certo número de operações sobre seu corpo e sua alma, pensamentos e condutas, obtendo assim uma autotransformação. O objetivo dessas técnicas consiste em alcançar certo estado de felicidade, sabedoria, pureza ou imortalidade (FOUCAULT, 1990, p.48).

Assim, Foucault aproxima-se do problema da formação do sujeito: "[...] não é o poder, mas o sujeito, que constitui o tema geral de minha pesquisa." (FOUCAULT, 1995, p. 232). Cada matriz tecnológica implica certo modo de educação e de transformação dos indivíduos. Contudo, o que está em jogo nas técnicas de si não é a aquisição de certas aptidões, mas a formação de certas atitudes (FOUCAULT, 1990, p. 48).

A partir das duas últimas tecnologias - as de poder e as de si mesmo - Foucault (1990) redescreve seu projeto nos termos de uma história crítica da subjetividade cujo objeto é entender como em nossa cultura, os seres humanos se tornam sujeitos. Nessa nova imersão Foucault volta seu olhar à antiguidade tardia e para cultura grecoromana. Sua missão foi mostrar como os modos de ocupação consigo mesmo se configurava como um dos princípios de maior 
significação para as atividades políticas. A chamada epimeleia heautou, transcrita pelos escritores latinos como cura sui, isto é, "tomar conta de si", parece-lhe ser um princípio importante para cidades. Ao mesmo tempo, uma das grandes regras de conduta da vida social e pessoal e um dos fundamentos da arte de viver (FOUCAULT, 1990, p.50).

Com isso, a problematização que se pode fazer diz respeito à presença, ou, a ausência dessas tecnologias de si mesmo nas instituições educativas que arregimentam a arte de governo pedagógico em virtude do ajuste racional e econômico entre tecnologias diversas. Carvalho (2010) chama de campo de experimentação de subjetividades ativas as possibilidades que se tem nessa relação com as técnicas de si. Escreve Carvalho (2010, p. 62):

[p]arece-me, então, que desde longe, o cuidado e o interesse com a formação humana, no Ocidente, destinou-nos - todos que fomos (e ainda somos) formados e formamos - a um tipo de homopedagogismo por onde preponderou o déficit pedagógico, a conclusão finalizante, o governo fundamentado numa racionalidade e dimensão analítica do poder.

Nesse registro, contemporaneamente, Pagni (2010) alertou como esvaziamento da problematização ética, e, Carvalho (2010) como déficit contemporâneo da formação humana. Um problema a ser trabalhado nesse horizonte dos processos de subjetivação. Na entrevista $O$ retorno da moral Foucault (2004b, p. 262) afirma que nós contemporâneos não problematizamos certo número de questões que dizem respeito à constitui- ção ética do sujeito. Nesse contexto, o fenômeno da governamentalização aparece como o imbricamento de técnicas de dominação e de técnicas de si (FOUCAULT, 1990, p.49). Segundo o historiador Ramos do Ó:

[...] Foucault vai definindo aí um território de análise que permite cruzar permanentemente os domínios da ética com os da política. O termo gover-namentalidade $e$ a expressão tecnologias do eu, remetendo um para o outro e esclarecendo-se mutuamente, são os que melhor definem a inflexão operada nos seus últimos projetos de investigação, visando compreender as bases sobre as quais as modernas práticas da subjetivação têm vindo a ser construídas na modernidade. (Ó, 2014, p. 738).

A educação escolar articula-se no ajuste racional entre as capacidades objetivas, as redes de comunicação reguladas, as relações de poder desigual $e$ a dimensão das tecnologias de si mesmo que as instituições educacionais como dispositivos estratégicos na produção de subjetividades. No entanto, ao contrário das veridicções da cultura de si dos antigos que tinham por finalidade a constituição ético-política de si mesmo, por sua vez, os modernos processos de subjetivação assentam-se na condução dos homens pela verdade. Por isso, o bloco de capacidade-comunicação-poder não se refere somente aos regimentos internos e tarefas cumpridas no interior da instituição escolar, mas, diz algo sobre o próprio funcionamento do regime político de verdade que atravessa as instituições. O que é regulado são os modos pelos quais um indivíduo tem acesso à ver- 
dade com vistas a se tornar um sujeito da verdade (CANDIOTTO, 2012).

O governo da vida pela verdade constitui objeto de investigação dos cursos da década de 1980. O governo dos vivos (2014); Hermenêutica do sujeito (2006); O governo de si e dos outros (2010); e, A coragem de verdade (2011). Gros (2006) salienta que os processos de subjetivação ocidental ocorrem corpo-a-corpo com o dispositivo milenar de obediência, oriundo das técnicas de direção da consciência cristã. Foucault (1997b, p.102) resume o curso de 1980 com a seguinte interrogação:

[...] como é possível que, na cultura ocidental cristã, o governo dos homens exija daqueles que são dirigidos, para além de atos de obediência e de submissão, "atos de verdade" que têm como particularidade o fato de que não somente o sujeito é obrigado a dizer a verdade, mas dizer a verdade sobre si mesmo, suas faltas, seus desejos, seu estado d'alma etc.? Como se formou um tipo de governo dos homens em que não é mais exigido simplesmente obedecer, mas manifestar, enunciando aquilo que se é?

Seguindo Foucault (2014) é necessário situar saberes e práticas educacionais sobre essa relação de obediência, pois, os dispositivos pedagógicos da modernidade produzem sujeitos cujos discursos precisam se reconhecidos em atos requeridos de verdade:

[q]uando ele diz 'é verdade, logo eu me inclino' [...] não é a verdade da proposição que o obriga [...] é na medida em que ele faz lógica [...] porque ele mesmo se constitui, ou foi convidado a se constituir como operador num certo número de práticas ou como parceiro num certo tipo de jogo.(FOUCAULT, 2014, p. 89)

Conforme Ramos Ó (2014, p.739) o "[...] modelo de aluno autônomo que a escola tem vindo de há muito a promover, e sob tradições político-culturais as mais diversas, entronca por inteiro nesta tecnologia de governo [...]". Portanto, a própria autonomia, considerada um dos grandes ideais da formação humana após o iluminismo não deixar de ser um efeito de certo número de técnicas performativas de poder que incitam o sujeito a agir sobre seu corpo, desejos, vontades, pensamentos, comportamentos $e$ conduta em prol de um governo eficiente de si mesmo (Ó, 2014). Em Toronto, Foucault (1990) relaciona essa técnica de perscrutação interior, ou, arcana da consciência às exigências de verdade requeridas pelo modelo da confissão que o cristianismo fez funcionar como hermenêutica da carne, isto é, a decifração analítica e meticulosa dos próprios estados de consciência, uma leitura dos próprios pensamentos e dos traços de desejo (GROS, 2006).

Nos últimos anos de sua vida, Foucault procurou criar uma história crítica da subjetividade. Tal projeto separa-se, nitidamente, daquele formulado anos de 1970. Não mais uma genealogia da sujeição às máquinas de poder, mas, à história da produção das subjetividades. Isso não significou um retorno à ideia de sujeito, ou, uma conversão à interioridade do sujeito. Escreve Gros (2006, p. 128):

[...] no fundo, Foucault não cessa de insistir sobre o fato de que o 
sujeito suposto por essas técnicas de si, pelas artes da existência é um eu ético, antes que um sujeito ideal de conhecimento. Isto significa que o sujeito é compreendido como transformável, modificável: é um sujeito que se constrói, que se dá regras de existência e conduta, que se forma através dos exercícios, das práticas, das técnicas, etc.

Gros (2006, p.136), no pensamento de Foucault existe uma oposição entre um sujeito moral e um sujeito ético. O primeiro apóia-se na questão "quem é você?". Já o segundo procura responder: "o que você está fazendo de sua vida?". Na sutileza das perguntas repousa a diferença entre uma analítica da verdade e uma ontologia do presente. A questão "Quem sou eu?" não é um problema para a ética grega, pois se configura nos moldes próprios das técnicas cristãs de confissão. Sócrates não interpelava os outros, ou, a si mesmo com perguntas como: "Quem sou eu?", ao invés disso, o filósofo interpelava a todos para que cuidassem de si mesmo. Na interpretação de Gros (2006, p.136):

[q]uem sou eu? É uma questão que se articula através da relação instaurada entre o diretor de consciência e o seu dirigido, nos primeiros monastérios cristãos. Isso quer dizer que esta interrogação se inscreve num dispositivo preciso de obediência incondicional $e$ indefinida ao Outro, enquanto que a questão grega: $\mathrm{O}$ que você está fazendo de sua vi$\mathrm{da}$ ? Se inscreve num projeto pontual de liberação.
A questão "quem sou eu" relacionase com o imperativo da obediência compatível com a confissão. Esse dispositivo de obediência ressoa desde as primeiras críticas de Foucault à psicologia, as Ciências Humanas, bem como, na fixação autoritária e alienante de identidades nas práticas psiquiátricas (História da Loucura) e na regulação das existências pela determinação de condutas cientificamente estabelecidas como "normais" (Os anormais). Finaliza Gros (2006, p.138):

[...] o que nos aprisiona não é uma identidade abstrata, fixada pelas ciências humanas em estudos estatísticos, em detrimento de uma identidade concreta e pessoal que somente uma análise privada poderia fazer aparecer, mas é a busca mesma de uma identidade que, de cara, nos fixa em um dispositivo de obediência. Uma vez mais, porque a questão "Quem sou eu?" não é primeira, mas o eco no sujeito particular de uma injunção social, geral ("Quem é você?"), em que se fixa nossa dependência pela fixação de uma verdade singular que não existiu nunca, senão na promessa do Outro.

$\mathrm{Em}$ A ética do cuidado de si como prática da liberdade, Foucault (2004a), tece dura crítica a suspeita que existe em torno do preceito ético do cuidado de si em nossas sociedades. Em relação argumenta que o cuidado de si foi denunciado:

[...] como uma forma de amor a si mesmo, uma forma de egoísmo ou de interesse individual em contradição com o interesse que é necessário ter em relação aos 
outros ou com o necessário sacrifício de si mesmo. Tudo isso ocorreu durante o cristianismo, mas não diria que foi pura e simplesmente fruto do cristianismo. A questão é muito mais complexa, pois no cristianismo, buscar sua salvação é também uma maneira de cuidar de si. Mas a salvação no cristianismo é realizada através da renúncia a si mesmo. Há um paradoxo no cuidado de si no cristianismo, mas este é um outro problema. (FOUCAULT, 2004a, p. 268).

Percebe-se nos ditos de Foucault a importância e o peso que possuiu o dispositivo de renúncia de si mesmo, outrora, engendrado pelas práticas históricas do cristianismo na gestação das tecnologias de si que preponderam, apesar da distância, até o momento presente. $\mathrm{O}$ cristianismo possui uma noção de cuidado que se realiza na renúncia em prol da salvação. Além disso, é preciso levar em consideração que os atos de verdade, quer dizer, a obrigação de dizer a verdade sobre si mesmo baseadas no modelo da confissão, constituíram elementos eficazes para a profusão das racionalidades governamentais, principalmente em razão de seu ajuste com os mecanismos disciplinadores. Esse processo ocorreu no ponto de vista de Foucault (2012), porque as próprias formas de ligar o sujeito à verdade nas práticas cristãs se ampararam no modelo jurídico das obrigações, na qual a relação de obediência se colocava de modo incondicional entre dirigido e diretor da consciência.

\section{Considerações finais}

Em síntese, pode-se entender o percurso filosófico de Foucault nos fins da década de 1970 e início de 1980 como uma tentativa de superar os impasses da analítica do poder (COLLIER, 2011). Um problema que gerado junto às críticas que lhes foram dirigidas a hipótese da resistência. A possível acusação de certa impotência diante das relações microfísicas de poder levou Foucault a elaborar a noção de governo dos homens e traçar uma história das práticas de subjetivação do Ocidente. As matrizes tecnológicas de formação do sujeito, especialmente, as chamadas tecnologias de si permite alçar uma descrição histórica de modalidades de experiências ativas na constituição de si.

Diante do exposto, cabe-nos interrogar, quais horizontes que Foucault aponta para problematizar as técnicas de si no presente; e, que modos de experiência aspirar para mobilizar experiências de dessujeição nesses lugares que em a função-educador (CARVALHO, 2010) assume papel na condução da conduta do outro e no seu devir ético?

Nesse registro a questão da liberdade é muito importante. Um campo muito explorado ao remeter essa questão é do domínio da sexualidade. As grandes transformações que ocorreram na última metade do século $\mathrm{XX}$, somando ao fortalecimento dos movimentos em torno dos direitos das mulheres, dos negros, das minorias étnicas, dos gays, etc. Para Foucault (2004a, 267-268) essa mudança evidencia uma tensão que envolve de um lado liberação $e$, de outro, práticas de liberdade.

O tema da liberação se não for tratado com certo número de precauções e den- 
tro de certos limites corre o risco de remeter à ideia de que existe uma natureza ou uma essência humana. Tem-se a ideia de que existe uma natureza livre que após certo número de processos históricos, econômicos e sociais que a mascarou, alienou sob mecanismos de repressão se vê finalmente liberada em toda sua plenitude. É precisamente essa suposição de plenitude que precisamos nos livrar para compreender que as liberações somente abrem um campo de novas relações de poder. Caso contrário, corre-se o risco de não ultrapassar uma concepção meramente negativa das relações de poder, permanecendo no âmbito jurídico, da ordem da lei e do código. Nesse caso, o sujeito permanece ainda como produto de assujeitamento pelas técnicas de poder normalizador não havendo espaço para o sujeito ético que procura exercer um trabalho de si sobre si mesmo.

Segundo Foucault (2004a) existe formas genuínas de liberação, por exemplo, quando um povo colonizado procura se liberar do seu colonizador. Todavia, é necessário entender que a prática de liberação não basta para definir as práticas de liberdade que serão em seguida necessárias para que esse povo, essa sociedade e esses indivíduos possam definir para eles mesmos formas aceitáveis e satisfatórias da sua existência ou da sociedade política. Diz Foucault (2004a, p.266):

[é] por isso que insisto, sobretudo, nas práticas de liberdade, mais do que nos processos de liberação, que mais uma vez têm seu lugar, mas que não me parecem poder, por eles próprios, definir todas as formas práticas de liberdade. Trata-se então do problema com o qual me defrontei muito precisamente a respeito da se- xualidade: será que isso corresponde a dizer liberemos nossa sexualidade? O problema não seria antes tentar definir as práticas de liberdade através das quais seria possível definir o prazer sexual, as relações eróticas, amorosas e passionais com os outros? O problema ético da definição das práticas de liberdade é, para mim, muito mais importante do que o da afirmação, um pouco repetitiva, de que é preciso liberar a sexualidade ou o desejo.

Portanto, a liberação e a luta pela libertação em algum momento são de fato indispensáveis para a prática da liberdade. A liberação abre um campo de relações de poder, móveis, reversíveis e agônicas. Segundo Foucault (2004a, p.267) aqui é preciso introduzir a noção de dominação. As relações de poder têm uma extensão consideravelmente grande nas relações humanas estando completamente disseminadas no conjunto das relações sociais exercidas entre indivíduos, no seio de uma família, em uma relação pedagógica, ou, no corpo político em geral. Nesse campo extremamente complexo se encontram muitas vezes verdadeiros estados de dominação, nos quais as relações de poder, em vez de serem móveis e permitirem aos diferentes parceiros uma estratégia que os modifique estão bloqueadas e cristalizadas. Quando porventura um indivíduo, ou, um grupo social bloqueia o campo das relações de poder tornando-as imóveis e fixas estamos diante de um estado de dominação. No tocante à relação entre professor e aluno, diz Foucault (2004a, p. 284-285):

[n]ão vejo onde está o mal na prática de alguém que, em um dado jogo de verdade, sabendo mais do que um outro, lhe diz o 
que $\hat{e}$ preciso fazer, ensina-lhe, transmite-lhe um saber, comunica-lhe técnicas: o problema é de preferência saber como será possível evitar nessas práticas - nas quais o poder não pode deixar de ser exercido e não é ruim em si mesmo - os efeitos de dominação que farão com que um garoto seja submetido à autoridade arbitrária e inútil de um professor primário; um estudante, à tutela de um professor autoritário etc. Acredito que é preciso colocar es- se problema em termos de regras de direito, de técnicas racionais de governo e de êthos, de prática de si e de liberdade.

Consequentemente o problema ético nas nossas sociedades é o da prática da liberdade, pois, afinal o que é a ética senão a prática da liberdade, a prática refletida da liberdade.

\section{Referências}

ARAYA. A.S. La semántica biopolítica: Foucault y sus recepciones. Viña de Mar: CENALTES, 2014.

B UJES, M.I. Infância e Maquinarias. 2001. 246f. Tese (Doutorado em Educação). Faculdade de Educação, Universidade Federal do Rio Grande do Sul, Porto Alegre-RS, 2001.

CAMILLO, C. R. M. A avaliação como dispositivo pedagógico: capturas discursivas significadas no contexto da educação de surdos. 2008. 86f. Dissertação (Mestrado em Educação), Centro de Educação, Universidade Federal de Santa Maria, Santa Maria-RS, 2008.

CALIXTO, C. R. Querer, obedecer e empreender: o governo de si e dos outros nos discursos pedagógicos (final do século XVIII e início do século XIX). 2013. 144f. Tese (Doutorado em Educação) - Faculdade de Educação, Universidade de São Paulo-SP, 2013.

CARVALHO, A. F. Foucault $\boldsymbol{e}$ a função-educador: sujeição e experiências de subjetividades ativas na formação humana. Ijuí: Editora Unijuí, 2010.

COLLIER, Stephen J. "Topologias de poder: a análise de Foucault sobre o governo político para além da governamentalidade". Rev. Bras. Ciênc. Polít., Brasília-BR, v.?. n. 5, julho 2011.

COSTA, C.R.S. O pastorado cristão e o dispositivo pedagógico: elementos para uma arqueogenealogia da educação escolar. 2012. 181f. Tese (Doutorado em Educação) - Faculdade de Educação, Universidade de São Paulo, São Paulo-SP, 2012.

DARDOT, P.; LAVAL, C. A Nova Razão do Mundo: Ensaio sobre a Sociedade Neoliberal. São Paulo: Editora Boitempo, 2016

DELORS, J. Educação: um tesouro a descobrir. 2ed. São Paulo: Cortez; Brasília, DF: MEC/UNESCO, 2003.

FISCHER, R.M.B. "O dispositivo pedagógico da mídia: modos de educar na (e pela) TV". Educação e Pesquisa. São Paulo-SP, vol.28, n.1, p.151-162, jan-jun 2002. 
FREITAS, A. S. "A parresía pedagógica de Foucault e o êthos da educação como psicagogia". Revista Brasileira de Educação [en línea]. Rio de Janeiro-RJ.v.18.,n. 53, abr-junh 2013.

FREITAS, A.S. "O cuidado de si e os perigos de uma ontologia ainda sem cabimento: o legado ético-espiritual de Foucault". Pro-posições: Campinas-SP , v. 25, n. 2, p. 121-138, ago 2014.

FOUCAULT, M. Tecnologias del yo: y otros textos afines. Barcelona, Paidós, 1990a.

FOUCAULT, M. "O sujeito e o poder". In: DREYFUS, H. \& RABINOW, P. Michel Foucault, uma trajetória filosófica: para além do estruturalismo e da hermenêutica. Rio de Janeiro-RJ: Forense Universitária, 1995.

FOUCAULT, M. Vigiar e punir: nascimento da prisão. Petrópolis-RJ: Vozes, 1997.

FOUCAULT, M. Resumo dos cursos no Collège de France (1970-1982). Rio de Janeiro-RJ: Jorge Zahar, $1997 b$.

FOUCAULT, M. "A ética do cuidado de si como prática da liberdade". In: MOTTA, Manoel Barros da (org.). Ditos \& Escritos V - Ética, Sexualidade, Política. Rio de Janeiro-RJ: Forense Universitária, 2004a.

FOUCAULT, M. "O retorno da moral". In: MOTTA, Manoel Barros da (org.). Ditos \& Escritos V - Ética, Sexualidade, Política. Rio de Janeiro-RJ: Forense Universitária, 2004b.

FOUCAULT, M. A hermenêutica do sujeito. São Paulo-SP: Martins Fontes, 2006.

FOUCAULT, M. História da sexualidade I: a vontade de saber. $18^{\mathrm{a}}$ ed. Rio de Janeiro: Edições Graal, 2007.

FOUCAULT, M. Microfísica do poder. São Paulo: Editora Graal, 2008a.

FOUCAULT, M. O nascimento da biopolítica: curso no Collège de France. São Paulo: Martins Fontes, 2008b.

FOUCAULT, M. Segurança, território e população: curso no Collège de France. São Paulo: Martins Fontes, 2008c.

FOUCAULT, M. O governo de si e dos outros: curso no Collège de France. São Paulo: Editora WMF Martins Fontes, 2010.

FOUCAULT, M. A coragem de verdade: o governo de si e dos outros II. São Paulo: Editora WMF Martins Fontes, 2011.

FOUCAULT, M. Do governo dos vivos: curso no Collège de France (1979-1980). São Paulo: Martins Fontes, 2014.

GROS, F. "Situação do curso". In: FOUCAULT, M. A hermenêutica do sujeito. São Paulo-SP: Martins Fontes, 2006.

HAMANN, T. Neoliberalismo, governamentalidade e ética. Ecopolítica. São Paulo, v.3, p. 99133, 2012.

HATTGE, M. D. Performatividade e inclusão no movimento todos pela educação. 2014. $182 \mathrm{f}$.

Tese (Doutorado em Educação), Universidade do Rio dos Sinos, São Leopoldo-RS, 2014. 
KERN, G. S. Educar é eugenizar: racialismo, eugenia e educação no Brasil (1870-1940). 2016. 208f. Tese (Doutorado em Educação) - Faculdade de Educação, Universidade Federal do Rio Grande do Sul, Porto Alegre-RS, 2016.

KLEIN, R.R. Educação \& Voluntariado: uma parceria produtiva. 2005. 137f. Dissertação (Mestrado em Educação) - Universidade do Vale do Rio dos Sinos, São Leopoldo-RS, 2005.

LAZZARATO, M. Signos, máquinas, subjetividades. São Paulo: Edições Senac, p. 193-213, 2014.

LOCKMANN, K. Inclusão escolar: saberes que operam para governar a população. 2010. 180f. Dissertação (Mestrado em Educação) - Faculdade de Educação, Universidade Federal do Rio Grande do Sul, Porto Alegre-RS, 2010.

LOCKMANN, K. A proliferação das Políticas de Assistência Social na educação escolarizada:estratégias da governamentalidade neoliberal. 2013. 317f. Tese (Doutorado em Educação) - Faculdade de Educação, Universidade Federal do Rio Grande do Sul, Porto Alegre-RS, 2013.

MENEZES, E.C.P. A maquinaria escola na produção de subjetividades para uma sociedade inclusiva. 2011. 189f. Tese (Doutorado em Educação) - Universidade do Vale do Rio dos Sinos, São Leopoldo-RS, 2011.

MUSSETTA, P. "Foucault y los anglofoucaultianos: una reseña del Estado y la gubernamentalidad". Revista Mexicana de Ciencias Políticas y Sociales: Distrito Federal, México vol. LI, núm. 205, pp. 37-55, enero-abril, 2009.

Ó, J.R. "Questionando o social: governamentalidade, tecnologias do eu e a história da escola”. Lisboa Portugal: Análise Social, v.49,n.212,p.737-741, 2014.

PAGNI, P. A. "Infância, Arte de Governo Pedagógica e Cuidado de Si". Educação \& Realidade. Porto Alegre-RS, v.35, n.3, p. 99-123, set/dez 2010.

PAGNI, P. A. Experiência estética, formação humana e arte de viver: desafios filosóficos à educação escolar. São Paulo-SP: Edições Loyola, 2014a.

PAGNI, P. "Filosofia da Educação no Brasil: concepções, impasses e desafios para a sua constituição como campo de pesquisa e o seu ensino nas duas últimas décadas". Revista Educação e Filosofia, Uberlândia-MG, v. 28, n. 56, p. 773-808, jul./dez 2014 b.

PAGNI, P. Ética da amizade e deficiência: outras formas de convívio com o devir deficiente na escola. Childhood \& Philosophy, Rio de Janeiro, v. 12, n. 24, mai.-ago. p. 343-370, 2016.

PAGNI, P. "O ingovernável dos corpos e das multidões na escola: formação ética, resistência e alteridade radical.". In: RODRIGUES, A, C; BERLE, S; KOHAN, W (orgs). Filosofia e educação em errância: inventar escola, infâncias do pensar. 1 ed. Rio de Janeiro: NEFI, p.195-211, 2018.

PIECKOWSKI, T. M. Z. Inclusão de estudantes com deficiência na educação superior: efeitos na docência universitária. 2014. 208f. Tese (Doutorado em Educação) - Universidade Federal de Santa Maria, Santa Maria-RS, 2014. 
RECH, T. L. A emergência da inclusão escolar no governo FHC: movimentos eu a tornaram uma "verdade" que permanece. 2010. 183f. Dissertação (Mestrado em Educação) - Universidade do Vale do Rio dos Sinos, São Leopoldo-RS, 2010.

ROSE, N. El gobierno en las democracias liberales avanzadas: del liberalismo al neoliberalismo. Archipiélago, v. 29, p. 25-40, 1997.

ROSE, N. Como se deve fazer a história do eu?. Educação e Realidade: Porto Alegre, v. 26, n. $1,2001$.

SILVA, T. T. Documentos de identidade: uma introdução às teorias do currículo. 3. ed. Belo Horizonte-MG: Autêntica, 2010.

SANTOS, I. M. Inclusão escolar e a educação para todos. 2010. 210f. Tese (Doutorado em Educação) - Faculdade de Educação, Universidade Federal do Rio Grande do Sul, Porto Alegre-RS, 2010.

SEIXAS, R. L. R. A questão do governo: qual a relação entre éthos crítico e éthos parresiástico no último Foucault? 2012. 186f. Tese (Doutorado em Filosofia) - Instituto de Filosofia e Ciências Sociais, Universidade Federal do Rio de Janeiro, Rio de Janeiro-RJ, 2012.

SILVA, Débora Ferreira. A constituição do sujeito deficiente visual a partir do movimento de inclusão escolar: uma análise na perspectiva foucaultiana. 2017. 180 f. Tese (Doutorado em Ensino de Ciências e Educação Matemática) - Universidade Estadual de Londrina, LondrinaPR. 2017.

VEIGA-NETO, A. "Educação e governamentalidade neoliberal: novos dispositivos, novas subjetividades". In: COLÓQUIO FOUCAULT. Anais... Rio de Janeiro: Universidade Estadual do Rio de Janeiro, 1999.

VEIGA-NETO, A. Incluir para saber. Saber para excluir. Revista Pro-posições. Campinas-SP, v.12, n.2, 2001.

VEIGA-NETO, A; LOPES, M.C. "Inclusão e governamentalidade". Educação e Sociedade, Campinas-SP, v.28, n.100, p.947-963, out 2007.

VEIGA-NETO, A. Foucault \& a Educação. Belo Horizonte-MG: Autêntica, 2004.

Recebido em: 19/05/2020 Aprovado em: 18/10/2020 